\title{
A OFICINA DE VIVÊNCIA CINEMA E EDUCAÇÃO: UMA VISÃO INTERDISCIPLINAR NA ESCOLA
}

DOI: http://dx.doi.org/10.5965/198431781112015167

Sebastião Gaudêncio Branco de Oliveira ${ }^{1}$

\begin{abstract}
RESUMO
O relato de experiência desenvolve reflexões sobre a criação da oficina de vivência 'Cinema e educação: uma visão interdisciplinar na escola' realizada no II Encontro Catarinense do Programa Institucional de Iniciação à Docência, ocorrida em 21 de julho de 2014. A elaboração da oficina parte de observações em uma escola de Florianópolis, de um exercício audiovisual na Usina de Cinema, e debates e leituras advindos do PIBID Interdisciplinar da UDESC. A vivência volta-se para a equipe de cinema e a produção de uma narrativa audiovisual como eixo interdisciplinar passível de realização em diversos campos do saber no ensino fundamental quando o professor se apodera de dispositivos tecnológicos como ferramenta de aprendizado. A oficina possibilitou um exercício de docência aos alunos em formação; experimentação de mídias disponíveis no cotidiano; iniciação à linguagem cinematográfica por meio de um exercício de imagem e movimento; e a discussão sobre possibilidades de uso da criação audiovisual em sala de aula.
\end{abstract}

Palavras-chave: Interdisciplinaridade; linguagem cinematográfica; cinema e educação.

\section{CINEMA AND EDUCATION WORKSHOP EXPERIENCE: AN INTERDISCIPLINARY VISION AT SCHOOL}

\begin{abstract}
The experience report develops reflections on the creation of living workshop 'Cinema and education: an interdisciplinary approach in school' held in II Encontro Catarinense do Programa Institucional de Iniciação à Docência held on 21 July 2014. The preparation of the workshop goes by remarks at a school in Florianopolis, a visual exercise in Usina de Cinema, and discussions and readings arising from PIBID Interdisciplinary UDESC. The experience turns to the film crew and the production of an audiovisual narrative as an interdisciplinary axis capable of achievement in various fields of knowledge in elementary school when the teacher gets hold of technological devices as a learning tool. The workshop enabled an exercise in teaching students in training; Trial of media available in daily
\end{abstract}

1 Bacharel em Naturologia Aplicada pela Universidade do Sul de Santa Catarina - UNISUL. Acadêmico do curso de Licenciatura em Artes Visuais na Universidade do Estado de Santa Catarina - UDESC. Bolsista do Programa de Iniciação à Docência subprojeto interdisciplinar da Universidade do Estado de Santa Catarina desde março de 2014. 


\section{EDUCAÇÃO, ARTES}

VOLUME 11, NÚMERO 1, Ano 2015

E INCLUSÃO

life; introduction to film language through an image exercise and movement; and discussion on possible uses of audiovisual creation in the classroom.

Key words: Interdisciplinarity; film language; cinema and education.

\section{Introdução}

Este texto relata algumas das estratégias para implementação do Programa Institucional Bolsa de Iniciação à Docência (PIBID) subprojeto Interdisciplinar ${ }^{2}$ da Universidade do Estado de Santa Catarina (UDESC) na busca por uma temática que servisse de eixo interdisciplinar para o desenvolvimento do projeto "Educação Inclusiva na Escola: Uma Ação Interdisciplinar” que iniciou em 2014 e segue até 2018.

Os temas 'Cinema e Educação' foram suscitados durante as reuniões do grupo, onde os envolvidos demonstraram interesse em aprofundar o assunto, assim como formular e testar ações de caráter pedagógico envolvendo a temática tanto para questões de criação e produção audiovisual quanto para capacitação e usos de mídias tecnológicas. Além disso, havia o desejo de possibilitar que o 'Cineclube Presença' (iniciativa do Grupo de Pesquisa Educação, Arte e Inclusão) veiculasse sua programação de curtas nas escolas participantes do PIBID. Observou-se no decorrer de 2014, nas três escolas, filmes eram utilizados de diversas maneiras, inclusive como em momentos de "tapa-buraco" (MODRO, 2008), ou seja, como estratégia para preencher a ausência de algum professor, expondo assim, o despreparo para a contextualização de filmes intimamente ligados ao cotidiano dos alunos.

Modro (2008) sugere que no espaço escolar há carência de equipamentos adequados e muitas vezes nota-se também inaptidão ou falta de familiaridade dos professores para com as tecnologias de projeção, captação, edição e aspectos fundamentais a respeito do que se convencionou chamar de linguagem cinematográfica.

\footnotetext{
${ }^{2}$ Coordenado por Prof. a Dra. Ma Cristina da Rosa Fonseca da Silva e Prof. a Dra. Regina Finck Schambeck.
} 


\section{EDUCAÇÃO, ARTES}

VOLUME 11, NÚMERO 1, Ano 2015

E INCLUSÃO

ISSN 1984-3178

Desde o início, parecia claro o potencial de criar relações interdisciplinares tanto quanto para os alunos/professores quanto aos participantes da oficina, originários de distintas instituições e campos do saber. O cinema como linguagem dependente das tecnologias pode ser um eixo de reflexão sobre sua inserção nas escolas.

\section{Pré-produção - Observação e pesquisa}

Neste tópico serão expostos relatos de vivência enquanto alunos/professores em uma escola estadual de Florianópolis como elemento contextual para criação de uma oficina de vivência voltada para professores em formação inicial.

\section{$O$ contexto da escola visitada}

O trajeto começa com o PIBID da UDESC subprojeto interdisciplinar "Educação inclusiva na escola: uma ação Interdisciplinar" envolvendo alunos das licenciaturas nas graduações em Artes Visuais, Música, Pedagogia, Geografia e História. Voltando-se para a educação inclusiva, pesquisas interdisciplinares e instrumentalização quanto às novas mídias e tecnologias.

São 22 discentes atuando em três escolas municipais de Florianópolis subdividindo-se em três equipes contendo ao menos um aluno de cada curso. A Escola de Educação Básica Hilda Teodoro Vieira (EEBHTV) corresponde à equipe que desenvolveu a pesquisa e redigiu este ensaio, sendo dois alunos de artes visuais, dois de música, dois de pedagogia, um de geografia e um de história.

A proposta inicial advinda das coordenadoras de área voltou-se ao mapeamento do local. Conhecer a escola, os funcionários, os alunos, a dinâmica das atividades e as rotinas, além de apresentar-se como disponível às demandas de diversas ordens, desenvolvendo um diário de bordo, contendo registros de atividades, fotografias, anotações, apontamentos e fichamentos.

Iniciamos as visitas em abril de 2014 e constatou-se que, atualmente, a equipe de funcionários é composta por quatro pessoas encarregadas pelos serviços gerais, seis professores efetivos na escola, vinte e três professores substitutos, com contratos temporários (ACTs), cinco educadores readaptados, cinco cargos pedagógicos/administrativos e duas 
cozinheiras de serviço terceirizado. Verifica-se também que em 2001, a escola sob a direção de Eliane Fauth e Sônia Bastos recebeu o Prêmio Referência Nacional e em 2002 foi escolhida por uma pesquisa da Organização das Nações Unidas para a Educação, Ciência e Cultura (UNESCO) por ser uma escola inovadora e bem sucedida, atingindo seu objetivo que segundo a organização é a participação da comunidade na escola.

De 2002 até 2014, a estrutura da escola se modificou. A escola, atualmente, possui uma rádio equipada e gerida por alunos sem acompanhamento pedagógico ${ }^{3}$, sala de informática com apenas dois equipamentos em funcionamento, uma biblioteca com vasto acervo em literatura nacional e internacional, todavia pouco frequentada e sem profissional da área de biblioteconomia para organização do acervo. Além de um parque de diversões danificado e pouco utilizado, a escola possui sala de vídeo, com projetor e sessenta cadeiras (conquista da professora de artes), uma sala com instrumentos musicais fechada ${ }^{4}$ e a Sala de Apoio ao Estudante com Deficiência (SAED) que permaneceu inativa até outubro de $2014^{5}$.

A escola recebe atividades do programa "Mais Educação", criado pela Portaria Interministerial $\mathrm{n}^{\mathrm{o}}$ 17/2007 e regulamentado pelo Decreto 7.083/10, que compõe uma estratégia do Ministério da Educação para a construção da agenda de educação integral nas redes estaduais e municipais de ensino ampliando a jornada de ensino para 7 horas.

Por meio de observação, podemos notar que a escola está localizada em área nobre do bairro Trindade, na cidade de Florianópolis, Santa Catarina em uma avenida de grande circulação de veículos e pessoas, portanto, situada em uma região muito visada pela especulação imobiliária. Nas redondezas, escolas próximas passaram por reformas e ações, enquanto que a unidade onde desenvolvemos as atividades do PIBID, leva tempos para conseguir sequer uma pintura dos portões, o que nos possibilita pensar em um processo de

\footnotetext{
${ }^{3}$ A partir de maio, o grupo do Pibid Interdisciplinar, passou a organizar reuniões com alunos, professores e funcionários e prol da qualificação do uso da rádio escolar. Para tanto, um encontro semanal com a equipe é realizado nas dependências da biblioteca.

${ }^{4}$ De agosto até dezembro alunos do Pibid Interdisciplinar que cursavam música, passaram a ministrar semanalmente aulas de violão.

${ }^{5}$ Em outubro de 2014 a sala recebeu uma professora capacitada na área de educação especial e que passou a desenvolver atividades na sala.
} 


\title{
EDUCAÇÃO, ARTES
}

sucateamento com fins políticos e comerciais. As afirmações partem da análise e olhar da incongruência da realidade com o discurso do governador do Estado que afirmou em entrevista à Andréa Leonora e Nícola Martins em 04 de agosto de 2014:

\begin{abstract}
Sobre a Educação, acredito que com os royalties do pré-sal e a vinculação para a Educação, estados e municípios terão mais recursos para investir. Isso vai permitir remunerar melhor o professor e continuar com obras. Hoje nós estamos com 700 escolas, das 1.144 que o Estado tem, recebendo reformas significativas. Temos um sistema de gestão inovador, pelo qual a escolha do diretor não é mais política, mas feita com base no plano de gestão técnico que cada candidato apresenta, passa pela Secretaria de Educação e vai para votação na comunidade escolar. Outra inovação importante foi o cartão de débito, que deu ao diretor autonomia para fazer a gestão da manutenção da unidade escolar. Também estamos aperfeiçoando muito a parte pedagógica ${ }^{6}$.
\end{abstract}

Da equipe que passou a visitar a escola, todos ficaram encarregados do mapeamento das características da escola, no entanto, havia demandas da professora supervisora do subprojeto PIBID, responsável pela disciplina de Artes, como a revitalização da estrutura do parque da escola, tornar a rádio escolar pedagógica, a criação de um cineclube e a criação de jogos inclusivos para a utilização em parceria com a professora da SAED, visto que esta última é a única demanda do PIBID Interdisciplinar.

\section{Relato da Usina de Cinema}

Como aperfeiçoamento da parte pedagógica, no mês de maio, a escola participou de sessões de exibição do festival 'Curta de Minuto' onde alunos do $5^{\circ}, 6^{\circ}, 7^{\circ}$ e $8^{\circ}$ ano matutino e vespertino assistiram o CD-ROM Minuteen composto por vinte curtas de um minuto realizados por alunos de escolas de diversos lugares do Brasil, envolvendo stop-motion, animação e atuação de alunos e professores. A exibição também ocorreu no dia da 'Família na Escola', onde pais e alunos puderam assistir a uma sessão. Esta atividade foi promovida pelo

\footnotetext{
${ }^{6}$ Argumento do governador reeleito em primeiro turno Raimundo Colombo. http://www.centraldediarios.com.br/entrevistas/pelo-estado-entrevista-raimundo-colombo-sc-em-1-lugar-projetoeleicoes-2014/2066.html acesso em $13 \mathrm{dez} 2014$
} 


\section{EDUCAÇÃO, ARTES}

VOLUME 11, NÚMERO 1, Ano 2015

E INCLUSÃO

ISSN 1984-3178

'Cineclube Presença', vinculado ao Grupo de Pesquisa Educação, Arte e Inclusão e ao Núcleo Pedagógico de Educação e Arte (NUPEART).

O NUPEART realizou uma oficina ministrada pelo professor/artista/pesquisador Silvio Brunno no laboratório de informática do centro de artes da UDESC com alunos do EEBHTV com objetivo de apresentar dados históricos sobre a montagem cinematográfica e realizar um exercício de imagem e movimento que consiste em usar uma fotografia para ser aplicada cinco vezes a função de brilho glamour na plataforma virtual de edição de imagem https://pixlr.com/, como descoberta do movimento em uma imagem estática. Ampliando a atuação da universidade enquanto complemento e qualificação da experiência dos alunos com as tecnologias, visto que na escola o laboratório de informática não supre as necessidades da instituição.

A ideia do cineclube tocou um dos estagiários que anteriormente havia participado da 'Usina de Cinema"7 que contou com a participação dos cineastas Fernando Leão e Marcelo Sabiá, complementado com orientações de montagem e edição de Júnior Amorim. Uma das atividades propostas ao grupo foi à construção de uma cena contendo cinco planos de fotografia justapostos lado a lado como exercício para a compreensão da lógica da montagem envolvendo o plano de filmagem como unidade formal básica.

$\mathrm{Na}$ Usina de Cinema, Fernando Leão apresentou um exercício para iniciar a compreensão da sequência de imagens que parte do corte seco como ferramenta essencial para a confecção do ritmo seja em película com cortes manuais ou por meio de programas de edição como o Adobe Premier CS5 e Final Cut podendo de acordo com os fins, ser até utilizado programas como Windows Movie Maker. A proposta foi executada em grupo, em tempo de dez minutos uma filmagem contendo cinco planos fotográficos, que agrupados e justapostos formam uma cena. Disto espera-se que os planos aliados ao som ou não, criem um ou mais sentidos para uma cena. Desta proposição pensou-se na possibilidade de estruturar uma ação que envolvesse a relação de construção de uma cena para com a realidade de um grupo de alunos em formação de licenciatura não iniciados na criação audiovisual.

\footnotetext{
${ }^{7}$ Oficina de capacitação e fomento à criação audiovisual organizado pela Fundação Cultural de Lages em 2013 in: http://www.lages.sc.gov.br/site_novo/noticias.php?id_noticia=1699 acesso $14 \mathrm{dez} 2014$.
} 


\section{EDUCAÇÃO, ARTES}

VOLUME 11, NÚMERO 1, Ano 2015

E INCLUSÃO

ISSN 1984-3178

\section{Elementos da linguagem cinematográfica com potencial interdisciplinar}

O conceito de interdisciplinaridade é abordado por Fazenda (2010) tratando a questão da formação de professores, seja em níveis didáticos ou em práticas de ensino. Sugere que a interdisciplinaridade não pode se restringir somente à integração das disciplinas, pois a análise desse tipo de ações requer uma revisão das práticas pedagógicas dos professores, demandando destes, pesquisas que envolvam a cultura de seus locais de atuação. Segundo a autora é essencial o desdobramento dos saberes científicos às exigências sociopolíticas e econômicas, ampliando sua aplicabilidade devido à ineficiência de uma área apenas, sozinha, enfrentar uma problemática multifacetada. Isto lança a possibilidade de várias disciplinas voltarem-se para pesquisas com objeto comum, aos passos de uma consciência dialógica não linear, interativa, envolvendo saberes da experiência, saberes técnicos e saberes teóricos sem tendências hierárquicas, a partir da integração entre processo de criação e produtos de procedimentos pedagógicos (FAZENDA, 2010).

Para Lenoir (apud AUGUSTO, 2007), a interdisciplinaridade se estabelece em três planos: a interdisciplinaridade curricular, a interdisciplinaridade didática e a interdisciplinaridade pedagógica. A interdisciplinaridade curricular se estabelece no âmbito administrativo, na construção do currículo escolar; define o lugar, os objetivos e programas de cada disciplina. A interdisciplinaridade didática compreende o planejamento do trabalho interdisciplinar a ser realizado, aproximando os planos específicos de cada disciplina, de modo que os conteúdos possam ser mais facilmente integrados. E, por fim, a interdisciplinaridade pedagógica, que trata da prática pedagógica interdisciplinar, isto é, aquela que ocorre na sala de aula.

Tomando os apontamentos dos autores abordados anteriormente, nossa pesquisa voltou-se para explorar a construção de uma oficina direcionada para professores em formação, relacionando as tecnologias com a linguagem cinematográfica como possibilidade de prática pedagógica interdisciplinar em sala de aula. Ou seja, os objetivos voltaram-se para a capacitação do profisssional da educação a utilizar elementos da linguagem cinematográfica como objeto de pesquisa para ações em sala de aula, a partir de uma narrativa audiovisual elaborada em grupo em que os temas podem variar, de acordo com os objetivos pré-definidos ou não pelo professor. 


\title{
EDUCAÇÃO, ARTES
}

VOLUME 11, NÚMERO 1, Ano 2015

E INCLUSÃO

O dicionário teórico e crítico de cinema de Jacques Aumont e Michel Marie (2003) destaca que

\begin{abstract}
Ver um filme é, antes de tudo, compreendê-lo, independentemente de seu grau de narratividade. É, portanto, que em certo sentido, ele "diz" alguma coisa, e foi a partir dessa constatação que nasceu, na década de 1920, a ideia de que, se um filme comunica um sentido, o cinema é um meio de comunicação, uma linguagem (...) o "cinema intelectual", em particular, implicava a possibilidade de articular sequências de planos em razão de um sentido a ser produzido. (...) o cinema não tem língua, tem códigos - em grande número-, e cada um rege, de um ponto de vista parcial e particular, certos momentos ou certos aspectos dos enunciados fílmicos. O conjunto dos códigos do cinema é, portanto, globalmente, uma espécie de equivalente funcional da língua, sem ter seu lado sistemático.
\end{abstract}

A dinâmica de Fernando Leão $^{8}$ torna visível ao menos quatro códigos básicos: o roteiro da cena, o plano fotográfico, os aspectos formais (enquadramento), o áudio, a edição e a exibição. Estes elementos gerais se fundem pela interação da equipe, pelo aparelho de captação, pelo programa de edição e sua exibição. Anterior à execução foi explicitado ao grupo de forma dialogada os temas: Obra documental, Obra Ficcional e Obra Experimental, descrevendo sobre os três aspectos para a construção e criação de uma obra ou exercício audiovisual. Estes pressupostos introdutórios foram traduzidos pelos discentes na oficina, de modo a simplificar o exercício e dar possibilidades de estrutura formal.

A ficção atua por meio da representação audiovisual criada por pessoas que até então não se conhecem, de caráter imaginativo. O Caráter experimental surge por diversos lados, um deles é o uso do equipamento Ipod Apple Inc. de posse do Laboratório Interdisciplinar de Formação de Educadores (LIFE) da UDESC, disponíveis para uso dos estagiários realizadores da oficina. Outra forma de experimentalismo parte de ver-idealizar-realizar as características compositivas do enquadramento aparecendo também na montagem. O espaço-lugar de entorno donde a oficina será executada servirá de cenário, nisto o participante precisará explorar territórios do ambiente possível.

\footnotetext{
${ }^{8}$ Usina de Cinema, Fundação Cultural de Lages, 2013. A dinâmica é composta por relatos de experiência do acadêmico que participou desta.
} 


\section{EDUCAÇÃO, ARTES}

VOLUME 11, NÚMERO 1, Ano 2015

E INCLUSÃO

ISSN 1984-3178

A experiência que se materializa no corpo/pensamento do grupo a executar a filmagem, criará as ideias que se configurarão em roteiro que serão modeladas a partir da vivência de cada integrante, apresentando um tom de imprevisibilidade. É de fundamental importância a face documental da ação, pois se registrará a conexões entre a proposta de 'formar uma narrativa audiovisual', agregada a 'experiência do grupo participante-atuante' com a 'intencionalidades de sentidos', verificáveis na verbalização sobre o processo de criação, durante a exibição da produção que resulta em uma composição singular.

A pré-produção corresponde à estruturação da equipe, a escrita do roteiro e articulação da produção como escolha de locais adequados à proposta e outras parcerias, que, eventualmente, se tornem necessárias. Na fase de produção em si, o roteiro torna-se guia de execução, baseando-se nas articulações da pré-produção. Neste momento ocorrem as captações que podem ser com câmeras portáteis amadoras, câmeras de celulares, tablet, ou até com desenho sobre papel como em um story board. A pós-produção configura-se como o momento para a decupagem ${ }^{9}$, fase em que se seleciona o que irá para a sequência na montagem e edição, além da execução do plano de difusão.

Tendo a proposição com forma Ficção-Experimental-Documental parte-se para a formação da equipe. É necessário abordar a distribuição dos papéis e sua interdependência. Para esta fase pensou-se na dinâmica de escrever e colar na testa. A estratégia serve para que os outros membros do grupo pudessem sugerir possibilidades de ação, ou seja, a pessoa que não vê o que há escrito procura descobrir qual função está sendo sugerida em seu corpo. Entende-se que neste momento inicia-se a troca e o compartilhamento de saberes entre os integrantes, podendo sugerir a interdisciplinaridade em prática.

Para todas as fases se concretizarem é primordial a articulação da equipe, pois cada papel é fundamental em relação ao outro, e todos devem manter comunicação constante. Neste instante, configura-se uma ação interdisciplinar com os papéis principais que são: diretor, diretor de fotografia, operador de câmera, diretor de arte, assistente de arte, sonoplasta, operador de som, figurinista, cenógrafo, continuísta, maquiador, eletricista,

\footnotetext{
9 De acordo com o Dicionário de Jacques Aumont e Michel Marie o termo surgiu na década de 1910 com a padronização dos filmes e designa a 'decupagem' em cenas do roteiro, primeiro estágio da preparação do filme no papel, servindo de referência para a equipe técnica.
} 


\section{EDUCAÇÃO, ARTES}

VOLUME 11, NÚMERO 1, Ano 2015

E INCLUSÃO

ISSN 1984-3178

pesquisador, roteirista, gerente de produção, assistente de produção, entre outros de acordo com demandas estipuladas pelas equipes, conselhos e instituições como abordado por Modro (2008).

\section{"Nas entrelinhas do cinema" de Nielson Ribeiro Modro}

Quando buscávamos referências bibliográficas a respeito do uso do cinema em sala de aula, encontramos o projeto Cineducação: site de apoio didático, para professores, para a utilização de filmes em sala de aula. Projeto de extensão desenvolvido na Universidade da Região de Joinville (UNIVILLE), vinculado ao departamento de Letras e organizado por Nielson Ribeiro Modro tanto na versão impressa quanto no sítio virtual ${ }^{10}$. O projeto teve como objetivo a pesquisa sistematizada de filmes que possam ser utilizados em sala de aula com finalidade didática se opondo à estrutura secular da sala de aula, onde há um professor na frente de dezenas de alunos alinhados, enfileirados sentados e ouvindo conteúdos a serem trabalhados (MODRO, 2008, p.13). Assim proporciona ao aluno suporte e incentivo à pesquisa, não se limitando aos livros didáticos.

O autor comenta que o trabalho com a linguagem cinematográfica no ensino fundamental e médio, em diversas disciplinas, pode explorar: períodos históricos em níveis de diálogos e reconstruções, marcas enunciativas dos produtores dos filmes, interpretação das imagens e sons, saberes interdisciplinares e valores éticos, morais e educacionais. No entanto é essencial que o professor, esteja preparado para utilizá-lo aproveitando o que há de melhor neste meio, pois a questão não é o quanto isto é utilizado e, sim, se este uso é feito de modo eficiente ou não (MODRO, 2008).

As pesquisas do projeto "Cineducação" voltam-se para a análise de filmes de caráter comercial, pois se considera que há filmes mais indicados que outros para abordar determinados assuntos em públicos específicos, "Portanto a regra é: adequar filmes a espectadores que tenham o discernimento e a maturidade adequados aos mesmos". (MODRO, 2008, p.17). O autor prescreve cuidados já que "todos os filmes são apenas uma representação

\footnotetext{
${ }^{10}$ http://www.modro.com.br/cinema/
} 


\section{EDUCAÇÃO, ARTES}

VOLUME 11, NÚMERO 1, Ano 2015

E INCLUSÃO

ISSN 1984-3178

do real", ou seja, possuem sempre uma visão segmentada devido ao caráter do vídeo que possui um inicio, um meio e um fim. O filme, segundo o autor, seria incapaz de apreender todas as histórias de todos os tempos, tornando a interpretação das informações contidas na mídia analógica ou digital uma possível análise, pois os fatos por mais "verossímeis que parecem ser, são um recorte de mundo" (MODRO, 2008). A oficina que se fundamenta nos textos acima, organizada pelo PIBID Interdisciplinar, volta-se não para o uso de filmes em sala de aula, e sim, para ao estímulo para professores em formação, de serem capazes de relacionar tecnologias da linguagem visual do cinema com seus próprios modelos educacionais, tal qual ressaltado por Nielson Modro, e, ao mesmo tempo, observando-se o espaço da escola Hilda Teodoro Vieira. O autor sugere

[...] se possível utilizar os temas de forma interdisciplinar, interligando com outras disciplinas e buscando a horizontalização na discussão dos assuntos abordados. Para isso pode-se utilizar o conteúdo (enredo/narrativa), a linguagem (verbal/visual/sonora), os aspectos técnicos, temas e desdobramentos temáticos possíveis (MODRO, 2008, p.19).

$\mathrm{Na}$ citação acima, o autor sugere elementos essenciais, de modo claro e objetivo, enquanto possibilidades para a exploração de conteúdos que envolvem a discussão do uso do cinema como ferramenta crítica, poética e técnica.

Com isso nos apropriaremos dos aspectos técnicos do livro Nas entrelinhas do cinema $\left(\right.$ MODRO, 2008) ${ }^{11}$ correspondentes à formação da equipe de produção do capítulo 08 equipe de profissionais; a linguagem cinematográfica nos capítulos 07 roteiro, 06 fotografia, 02 enquadramentos, 03 ângulos de câmera e 04 movimentos de câmera direcionados para a criação de uma narrativa audiovisual em cinco planos pois:

Quanto aos aspectos técnicos das produções trata-se de uma ferramenta a mais no julgamento crítico de filmes, possibilitando ampliar ainda mais as possibilidades de trabalhos. Ter uma noção de como funciona sua criação é uma possibilidade a mais na leitura e análise do mesmo, sendo portanto uma ferramenta essencial para quem quer ou necessita realizar uma leitura aprofundada e cuidadosa acerca de alguma criação audiovisual. Acrescenta-se ainda que, a partir do conhecimento do como funciona tem-se a possibilidade de ampliar ainda mais os trabalhos, eventualmente

11 A obra está disponível para download do PDF e de outras publicações na página http://www.modro.com.br/cinema/livros.htm Acesso em $15 \mathrm{dez} 2014$. 


\section{EDUCAÇÃO, ARTES E INCLUSÃO}

VOLUME 11, NÚMERO 1, Ano 2015

ISSN 1984-3178

podendo construir as próprias obras e criando um envolvimento ainda maior de todos os interessados (MODRO, 2008, p.22).

Partiremos à produção em si, que se configurará em uma proposição com aproximações à leitura de Modro (2008) sobre as possibilidades de ampliar o uso crítico de filmes, enquanto leitura, análise, e criação audiovisual. Configurando uma tríade pensamento/teoria/prática apto à construção de equipes com potencial de envolvimento entre estudantes/professores na elaboração de uma narrativa sobre uma temática escolhida em interação.

\section{Produção - A forma da oficina e plano de execução}

Exposto a base de saberes para a construção da proposta de oficina de vivência, nesta unidade apresentaremos o plano de execução (APÊNDICE 1) como projeto piloto de uma proposição interdisciplinar formulada a partir da pesquisa anterior 


\section{EDUCAÇÃO, ARTES}

VOLUME 11, NÚMERO 1, Ano 2015

E INCLUSÃO

Tabela 1- Proposta de Oficina "Vivência Cinema e Educação: uma visão interdisciplinar na escola"

Título: Oficina de Vivência Cinema e Educação: uma visão interdisciplinar na escola

Tempo estimado: 4 horas.

Supervisores: Prof. ${ }^{a}$ Dra. $\mathrm{M}^{\mathrm{a}}$ Cristina da Rosa Fonseca da Silva e Prof. ${ }^{\mathrm{a}}$ Dra. Regina Finck Schambeck

Orientador na escola: Prof. a Adriana Durante

Bolsistas: André Durante Piva (história), Júlia Nascimento (artes visuais), Matheus Balbinoti (geografia), Sebastião G. B. de Oliveira (artes visuais).

Número de participantes: Máximo 25 pessoas.

Recursos materiais: Projetor de vídeo, computador com acesso à internet e programa de edição de vídeo, 5 tablets ou celulares com câmera de vídeo, câmera filmadora para documentação, 25 cópias impressas da proposta.

Ementa: O cinema como fio condutor para uma proposta interdisciplinar em sala de aula. Imagem e movimento como possibilidade pedagógica. Introdução a elementos da linguagem cinematográfica. Uso de tecnologias na educação.

Resumo: A oficina relata algumas das estratégias para implementação do PIBID Interdisciplinar na busca por uma temática que servisse de eixo interdisciplinar para o desenvolvimento do subprojeto EDUCAÇÃO INCLUSIVA NA ESCOLA: UMA AÇÃO INTERDISCIPLINAR. Utilizamos o tema do Cinema e suas relações interdisciplinares como estratégia de aproximação das escolas e construção coletiva do subprojeto. O cinema como linguagem dependente das tecnologias pode ser um eixo de reflexão sobre sua inserção nas escolas, considerando a Lei $\mathrm{n}^{\circ} 13006$ de junho 2014. Na oficina pretendemos ressaltar também as possibilidades estéticas, bem como fonte de conhecimento de diferentes saberes por meio da criação, execução e apresentação de uma narrativa audiovisual.

Objetivo geral: Proporcionar ao participante a experienciação de elementos da linguagem cinematográfica enquanto ferramenta prática e tecnológica para formar um eixo interdisciplinar de construção de conhecimento. Percorrer em tempo de 4h os estágios de uma criação cinematográfica: formação da equipe, construção de roteiro, produção e captação, pós-produção edição e exibição. Debater sobre o uso da proposta em sala de aula.

Fonte: elaborado pelos autores 


\section{EDUCAÇÃO, ARTES}

\section{Pós-produção - Análise dialética dos resultados}

O presente relato configura-se como uma articulação entre ensino, pesquisa e extensão com análise dos diários de anotações dos bolsistas e do referencial teórico para a montagem da proposição. Optamos por criar uma oficina denominada Cinema e Educação: Uma visão interdisciplinar na escola, para execução no dia 21/07/14 no II Encontro Catarinense do PIBID: Docência na Educação Básica: Ineditismo, Imprevisibilidade, Interculturalidade na Universidade do Vale do Itajaí (UNIVALI) com um grupo heterogênio-específico não iniciado na prática audiovisual. Esta ação foi readaptada e realizada em outros três eventos educacionais: Arte no Campo, X Anped Sul, Encontro Pibid Udesc (2014). A oficina não foi realizada na escola pesquisada, sendo que a vivência no espaço escolar atuou como inspiração à elaboração da proposição.

Imagens do produto da oficina de vivência não foram utilizadas para análise dos resultados devido à ausência do Termo de Consentimento Livre e Esclarecido de Uso de Imagem (TCLEUI). Entendemos que as imagens seriam documentos ricos para uma análise sistemática, enquanto suas possibilidades vivenciais, artísticas e estéticas. No entanto, em função do foco no processo de construção da oficina, este item não foi incluído, exceto o que havia na forma de texto nos diários de campo dos estagiários. Este tópico dedica-se a expor relatos dos alunos/professores em uma das oficinas realizadas.

\section{Encontro Catarinense do PIBID}

Realizamos a oficina denominada 'Cinema e Educação' com um grupo de 20 inscritos previamente e 8 na hora da realização da atividade, totalizando 28 participantes que foram subdivididos em 6 grupos. A proposta de trabalho tinha como base a criação de uma ferramenta capaz de percorrer processos interdisciplinares e colaborativos durante a criação 


\section{EDUCAÇÃO, ARTES}

VOLUME 11, NÚMERO 1, Ano 2015

E INCLUSÃO

ISSN 1984-3178

de uma narrativa audiovisual em 5 planos fotográficos, resultando em documentos audiovisuais de 30 segundos, concebido, realizado, editado, exibido e discutido durante a oficina com equipamentos fornecidos pelos mediadores.

Iniciamos com uma dinâmica de reconhecimento das funções de uma equipe de criação no cinema. Devido à excessiva quantidade de participantes, para o jogo de adivinhação o grupo foi dividido em dois grupos. Escrevemos os seguintes cargos em papéis que foram colados na testa de cada integrante da roda, com intuito do grupo sugerir ações correspondentes aos cargos. Estes eram: Diretor, Diretor de Fotografia, Operador de Microfone, Montador, Roteirista, Cenógrafo, figurinista, pesquisador, Assistente de produção, Produtor de arte, supervisor de pós-produção, sonoplasta e gerente de produção. Os propositores da oficina também participaram da dinâmica.

Após todos descobrirem o que estava escrito em cada papel, foram explanadas as características essenciais básicas da linguagem cinematográfica, como: Produção ficcional, documental e experimental. Justaposição de Imagens, Plano, Cena, Sequência e Take. Então foi mostrada a tabela de planos de fotografia (MODRO, 2008): grande plano geral, plano geral, plano conjunto, plano americano, plano médio, close, big close, plano detalhe, câmera sobre o ombro. Foi apresentado os movimentos de câmera plongée, contraplongée, e câmera subjetiva. Comentou-se também sobre traveling, tilt, zoom in e zoom out e o foco das lentes.

Daqui adentramos na proposta, que partiu da formação de 6 grupos com pelo menos 5 integrantes, e para cada grupo foi fornecido um tablet do laboratório LIFE e determinado o tempo de $1 \mathrm{~h} 30 \mathrm{~min}$ para todos definirem o tema de suas narrativas audiovisuais, os planos de filmagem para depois em um programa já instalado no equipamento foi possível a montagem de um vídeo curto de 30 segundos. 

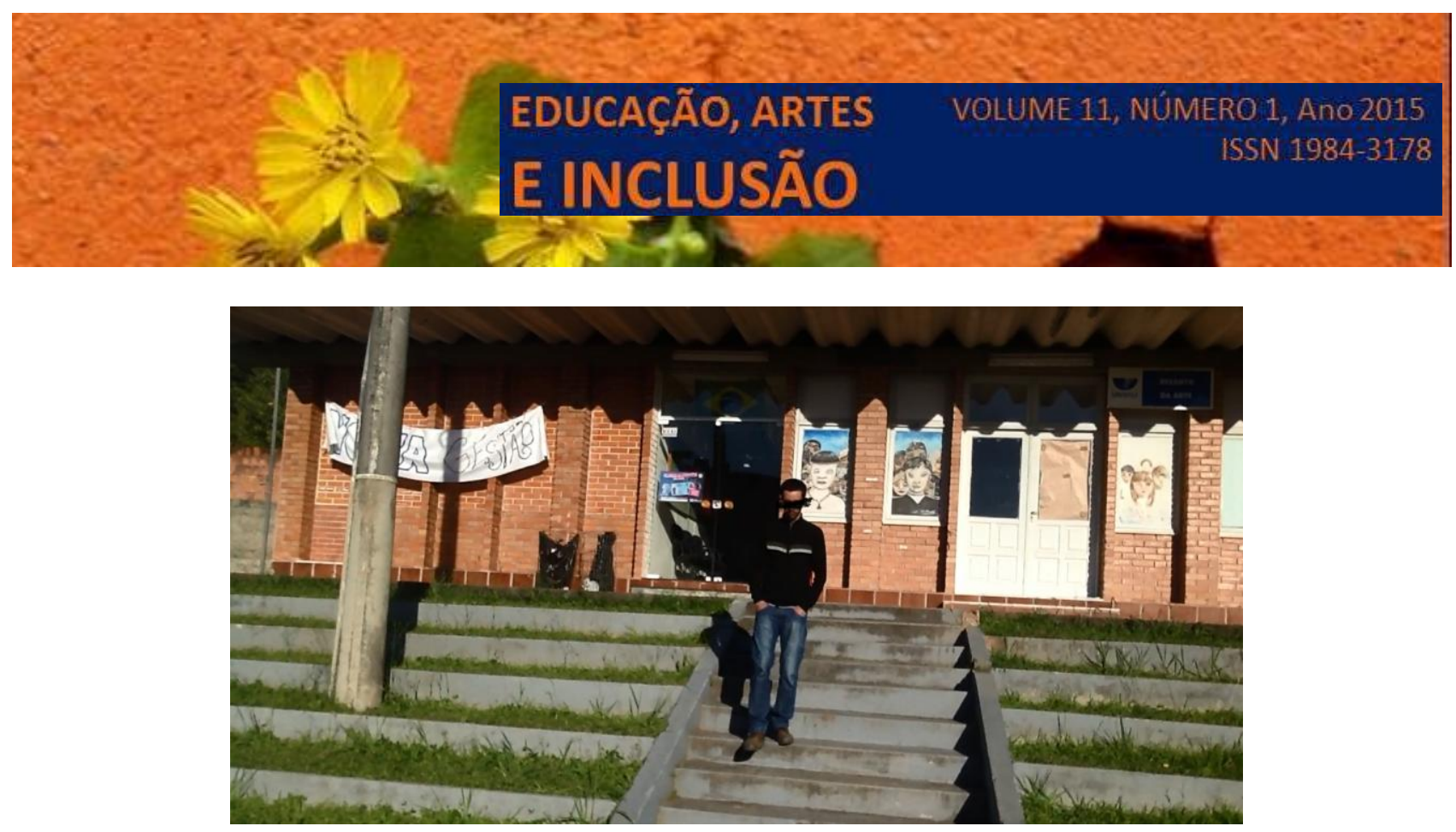

Still do vídeo Diálogos em três idiomas, grupo 3, grande plano geral. Arquivo do pesquisador, 2014.

As equipes saíram pelo campus da UNIVALI atrás de suas cenas, enquanto 1 grupo permaneceu na sala. Após a conclusão, cada grupo apresentou à turma o argumento e seus critérios de escolha frente à elaboração do tema, dos planos, dos acontecimentos da experiência de realização das filmagens e da edição. Os temas escolhidos pelos grupos foram: O encontro do PIBID como entrevista documental; A química e o meio ambiente como ficção informativa; Diálogos em três idiomas como ficção; A acessibilidade na UNIVALI como documental; Sobre as oficinas do encontro PIBID como documental; e Preconceito racial em sala de aula como ficção.

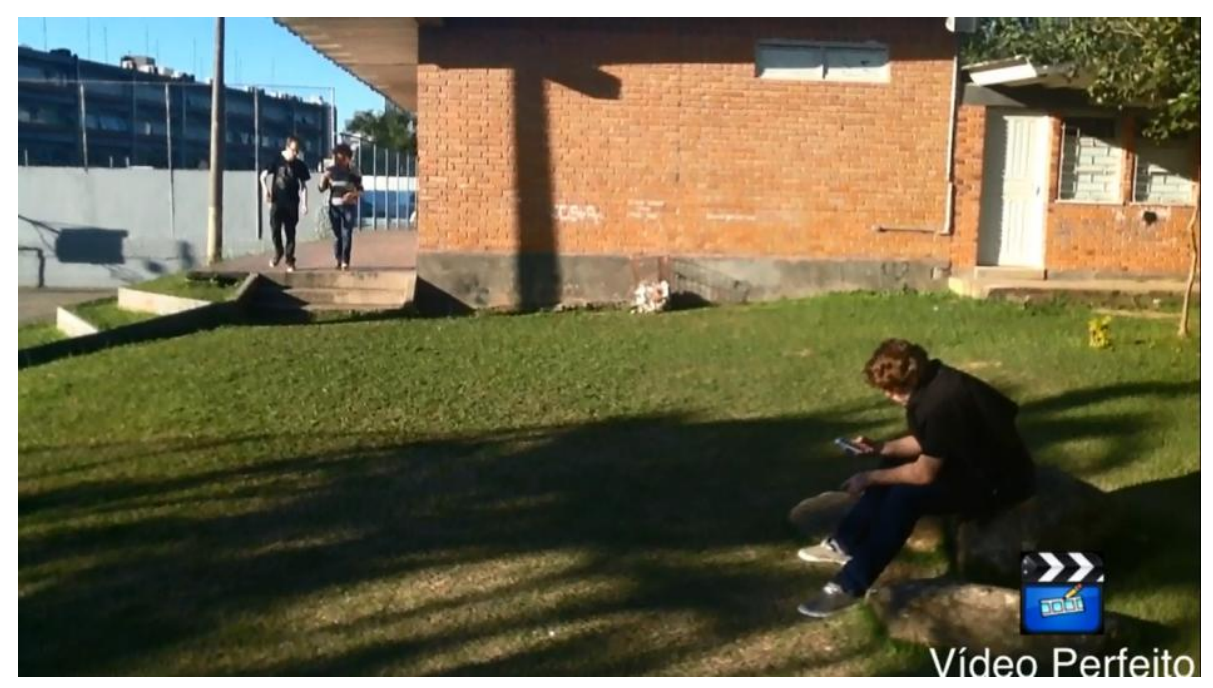

Still do vídeo A química e o meio ambiente, grupo 5, plano geral onde os personagem se aproximam da câmera. Arquivo do pesquisador, 2014. 


\section{EDUCAÇÃO, ARTES}

VOLUME 11, NÚMERO 1, Ano 2015

E INCLUSÃO

ISSN 1984-3178

Observou-se que a primeira dinâmica apresentou uma forma eficaz de criação de laços entre os participantes que não se conheciam e serviu também como ferramenta para se pensar a interdependência dos cargos de uma equipe de cinema como um vestígio de interdisciplinaridade, pois na prática real é visto que durante montagens de curtas-metragens de baixo orçamento, todos exercem igual ou semelhante influência na construção das cenas, podendo em alguns casos acumular funções. As equipes se formaram envolvendo discentes de diversas áreas do conhecimento, como letras, química, física, artes, história, geografia e sociologia, fato que acabou enriquecendo a construção pela inter-relação criada pelos diversos saberes e experiências individuais dos participantes. Os integrantes das equipes não eram familiarizados com a linguagem cinematográfica, mas assistindo aos vídeos, após a criação, ficou evidente o quanto o caráter experimental surgiu com frequência devido à estrapolação da proposta. Ao invés de somente 5 planos, que alguns grupos seguiram à risca, outros usaram 1 plano em movimento e outros em planos fora do exemplo inicial.

No fim da atividade, todos os grupos afirmaram perceber que aquele formato de atividade pode ser eficiente para uma construção interdisciplinar em sala de aula. As limitações da oficina voltaram-se para o download de programa de edição, pois todos os programas gratuitos permitem apenas 30 segundos de edição, e algumas equipes captaram mais tempo que isto. No entanto, esta limitação demanda do montador/editor, elaboração de um critério de corte aprofundado, levando a refletir sobre que elementos são essenciais para a constituição desta narrativa em forma de cena? Notou-se possibilidade para elaboração cênica enquanto formação de elenco, visto que todos os grupos apresentaram cenas em que os próprios integrantes atuavam como atores e coadjuvantes.

Devido à ausência do repasse da lista de inscritos pela organização do evento com seus devidos contatos, não foram enviados os vídeos aos participantes, nem materiais complementares, comprometendo a qualidade da oficina. Após este incidente, tomamos o cuidado de evitar que isto não se repetisse nas outras três atuações da oficina. 


\section{EDUCAÇÃO, ARTES}

\section{Considerações finais}

Ao considerarmos os objetivos da oficina quanto a proporcionar uma experienciação de criação a partir de elementos da linguagem cinematográfica, nota-se que todas as equipes formadas conseguiram concluir a atividade em diferentes níveis não mensuráveis de complexidade, cabe para próximas pesquisas verificar a aplicabilidade deste instrumento metodológico em classe com alunos de $6^{\circ}$ ao $9^{\circ}$. Acredita-se que seria essa a forma de se verificar a qualidade desta proposição, uma vez que estamos segerindo criações interdisciplinares em uma vivência interativa de construção de conhecimento aliada às problemáticas do cotidiano, visando a interdisciplinaridade pedagógica como estratégia de aprendizado de um tema elaborado em grupo.

Ficou claro aos realizadores da oficina, a importância de explorar relações para além da fotografia, como as sonoridades e atuação cênica, mesmo não havendo acadêmicos do curso de Artes Cênicas, fica a possibilidade de ampliação da questão de elenco e figurino, assim como cenário, iluminação e projeção da voz, que demandaria ampliação da carga horária

Em alguns momentos na partilha, onde olhávamos a produção, surgiram debates sobre planos fotográficos sem nomeá-los, mas que foram sinalizados de modo singular e reconhecível à grande maioria dos envolvidos, pois a compreensão do enquadramento foi a partir da figura de seu próprio corpo, em conformidade com os exemplos apresentados inicialmente.

Observou-se que alguns participantes da oficina, resolviam as cenas quase que rapidamente, sugerindo tanto familiaridade e apropriação de ferramentas tecnológicas, quanto pouco aprofundamento na leitura do ambiente e criação da cena. Alguns acreditavam não dispor de ferramentas, mas o que se observou é que não sabiam usar as que já tinham como o próprio programa do celular que manuseiam diariamente. Porém todas as cenas e takes apresentados na partilha, independente de seus elementos constitutivos e estruturais da linguagem visual, apresentaram possibilidades de debate, diálogos, apontamentos, notas, ideias, reflexões, discussões, controvérsias e também superficialidade e despreocupação. 


\section{EDUCAÇÃO, ARTES}

VOLUME 11, NÚMERO 1, Ano 2015 E INCLUSÃO

Alguns alunos deixaram a responsabilidade de manusear a câmera quase que exclusivamente à uns poucos, mais curiosos, mas no geral, todos os grupos se questionaram sobre quais os papéis dos profissionais e sobre a capacidade de envolver qualquer temática na construção de uma narrativa audiovisual. Este debate sugere a consolidação do objetivo de apresentação ao professor em formação uma ferramenta prática de uso de tecnologias em sala de aula tendo como meio o percurso (mesmo que em tempo reduzido) por alguns estágios de uma criação cinematográfica, passando pela formação de equipe interdisciplinar, elaboração de roteiro na pré-produção, o mapeamento de território e captação de takes em produção e edição e exibição acompanhado de discussão enquanto pós-produção.

Em última consideração nos inspiramos na Lei nº13.006 (24/07/2014) que acrescentou ao art. $\underline{\mathbf{2 6}}$ da Lei $\mathrm{n}^{\circ} \underline{\mathbf{9 . 3 9 4}}$, de 20 de dezembro de 1996, que estabelece as diretrizes e bases da educação nacional, a obrigatoriedade de exibição de filmes de produção nacional nas escolas de educação básica. A exibição de filmes nacionais constituirá componente curricular complementar integrado à proposta pedagógica da escola, sendo a sua exibição obrigatória por, no mínimo, 2 (duas) horas mensais ${ }^{12}$. Este fato político nos lança à sonhar com a possibilidade futura de exibições das produções audiovisuais de alunos em suas escolas e quem sabe pensar em trocas entre escolas.

\footnotetext{
${ }^{12}$ http://www.jusbrasil.com.br/ Acesso em 15 dez 2014.
} 


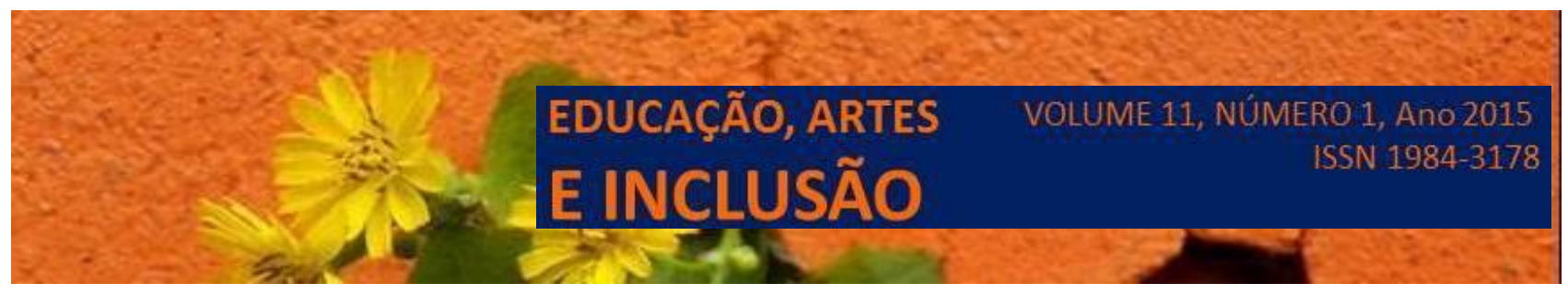

\section{Referências}

AUGUSTO, Thaís G.; CALDEIRA, Ana M. Dificuldades para a implantação de práticas interdisciplinares em escolas estaduais, apontadas por professores da área de ciências da natureza. Investigações em Ensino de Ciências. V12, PP.139-154, 2007.

AUMONT, Jacques; MARIE, Michel. Dicionário teórico e crítico de cinema. Ed Papirus. Campinas, São Paulo, 2003.

FAZENDA, Ivani C. A. Interdisciplinaridade e Transdisciplinaridade na formação de Professores. Ideação (Unioeste. Impresso), v. 10, p. 93-105, 2010.

MODRO, Nielson R. Nas entrelinhas do cinema. 1. ed Joinville: Ed. da UNIVILLE, 2008. 
Apêndice 1 - Planejamento da oficina de vivência Cinema e Educação: uma visão interdisciplinar na escola.

\begin{tabular}{|c|c|c|c|c|}
\hline $\begin{array}{c}\text { Temp } \\
\text { o }\end{array}$ & Con & Objetivos & $\begin{array}{l}\text { Procedimento } \\
\text { pedagógico }\end{array}$ & $\begin{array}{c}\text { Procedimento } \\
\text { de criação }\end{array}$ \\
\hline $30 \mathrm{~min}$ & $\begin{array}{lr}\begin{array}{l}\text { Apresentação } \\
\text { grupo. }\end{array} & \text { de } \\
\text { Apresentação } & \text { das } \\
\text { observações } & \text { na } \\
\text { escola } & \end{array}$ & $\begin{array}{l}\text { Criar vínculo com o } \\
\text { grupo. Expor e } \\
\text { discutir sobre uso do } \\
\text { cinema em sala de } \\
\text { aula } \\
\text { independentemente } \\
\text { da disciplina. }\end{array}$ & $\begin{array}{l}\text { Apresentação } \\
\text { dialogada dos } \\
\text { ministrantes e dos } \\
\text { inscritos. } \\
\text { Questionamento } \\
\text { sobre a relação do } \\
\text { cinema e formas de } \\
\text { uso em sala de aula. }\end{array}$ & $\begin{array}{l}\text { Verbalização e } \\
\text { gestualidade } \\
\text { sobre } \\
\text { assuntos }\end{array}$ \\
\hline $30 \mathrm{~min}$ & $\begin{array}{l}\text { Relação entre } \\
\text { interdisciplinaridad } \\
\text { e e equipe de } \\
\text { produção } \\
\text { cinematográfica. } \\
\text { Jogo de } \\
\text { adivinhação. }\end{array}$ & $\begin{array}{l}\text { Incentivar debate } \\
\text { sobre } \\
\text { interdisciplinaridade } \\
\text { imaginário do grupo } \\
\text { sobre a composição } \\
\text { e interdependência } \\
\text { dos papéis de uma } \\
\text { equipe de produção. }\end{array}$ & $\begin{array}{l}\text { Exposição } \\
\text { dialogada sobre } \\
\text { capítulo EQUIPE } \\
\text { DE } \\
\text { PROFISSIONAIS } \\
\text { (MODRO, 2008). } \\
\text { Proposta de jogo de } \\
\text { adivinhação onde } \\
\text { todos sugerem sem } \\
\text { dizer o que é, o } \\
\text { nome de uma das } \\
\text { funções de equipe. } \\
\text { Todos apresentam } \\
\text { papéis com os } \\
\text { nomes colados na } \\
\text { testa. }\end{array}$ & $\begin{array}{lr}\text { Refletir } & \text { sobre } \\
\text { as funções } \\
\text { exercidas em } \\
\text { uma equipe de } \\
\text { produção } r \\
\text { partir de seus } \\
\text { repertórios } \\
\text { imaginários. } \\
\text { Neste momento } \\
\text { inicia-se uma } \\
\text { construção em } \\
\text { grupo, pois } \\
\text { precisam falar } \\
\text { sobre algo que } \\
\text { uma ras } \\
\text { pessoas não } \\
\text { pode ver/saber. }\end{array}$ \\
\hline $30 \mathrm{~min}$ & $\begin{array}{l}\text { Introdução à } \\
\text { linguagem } \\
\text { cinematográfica. } \\
\text { Roteiro, fotografia, } \\
\text { ângulos de câmera, } \\
\text { movimento de }\end{array}$ & $\begin{array}{l}\text { Expor e discutir } \\
\text { conceitos básicos a } \\
\text { partir da literatura. } \\
\text { Apresentar possíveis } \\
\text { formas de leitura e }\end{array}$ & $\begin{array}{lr}\text { Projeção de } & \text { slides, } \\
\text { explanação } & \\
\text { verbalizada } & \text { sobre } \\
\text { película e } & \text { vídeo } \\
\text { digital. } & \text { Plano } \\
\text { (unidade } & \text { básica }\end{array}$ & $\begin{array}{l}\text { Perguntas, } \\
\text { dúvidas, } \\
\text { apontamentos, } \\
\text { sugestões, } \\
\text { diálogos. Nota- } \\
\text { se que este }\end{array}$ \\
\hline
\end{tabular}




\section{EDUCAÇÃO, ARTES}

\begin{tabular}{|c|c|c|c|c|}
\hline & $\begin{array}{l}\text { câmera, } \\
\text { enquadramento } \\
\text { (Modro, 2008). }\end{array}$ & $\begin{array}{l}\text { criação a nível } \\
\text { narrativo, } \\
\text { sonoro e textual. }\end{array}$ & $\begin{array}{l}\text { entre cortes), cena } \\
\text { (conjunto de } \\
\text { planos), sequência } \\
\text { (grupo de cenas). } \\
\text { Destaque para takes } \\
\text { (número de vezes } \\
\text { em que o plano é } \\
\text { repetido). }\end{array}$ & $\begin{array}{l}\text { momento } \\
\text { suscita muitas } \\
\text { dúvidas ao } \\
\text { participante que } \\
\text { procura } \\
\text { relacionar os } \\
\text { elementos } \\
\text { comentados, } \\
\text { com seu } \\
\text { repertório } \\
\text { fílmico } \\
\text { mnemônico. }\end{array}$ \\
\hline $\begin{array}{l}\text { 1h } \\
30 \mathrm{~min}\end{array}$ & $\begin{array}{l}\text { Exercício de } \\
\text { criação. Formação } \\
\text { de equipes, escrita } \\
\text { de roteiro da cena, } \\
\text { captação de imagem } \\
\text { em movimento, } \\
\text { montagem e edição. }\end{array}$ & $\begin{array}{l}\text { Experiênciar } \\
\text { processo de } \\
\text { audiovisual } \\
\text { grupo. Utilização e } \\
\text { apropriação } \\
\text { equipamento } \\
\text { tecnológico } \\
\text { (LIFE). }\end{array}$ & 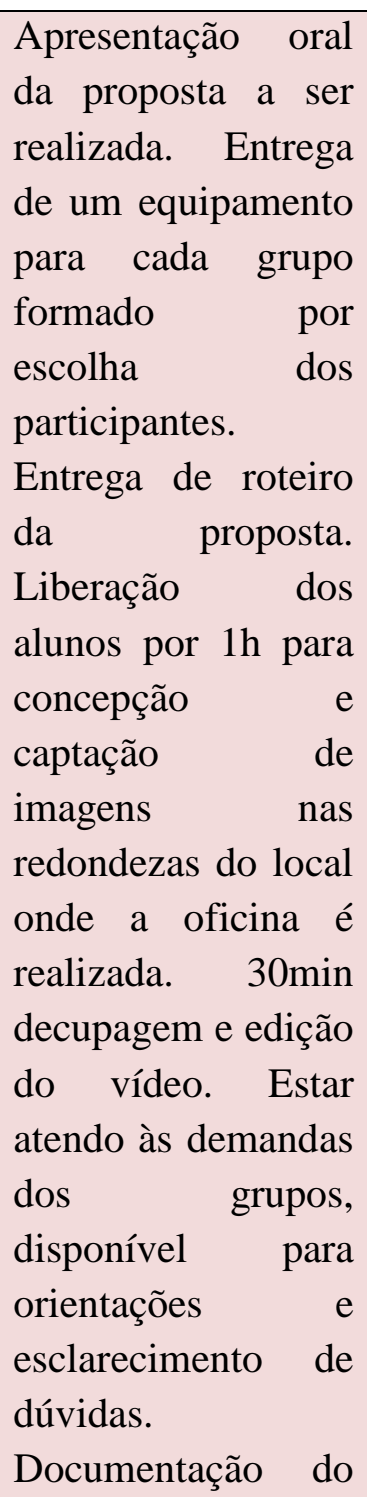 & 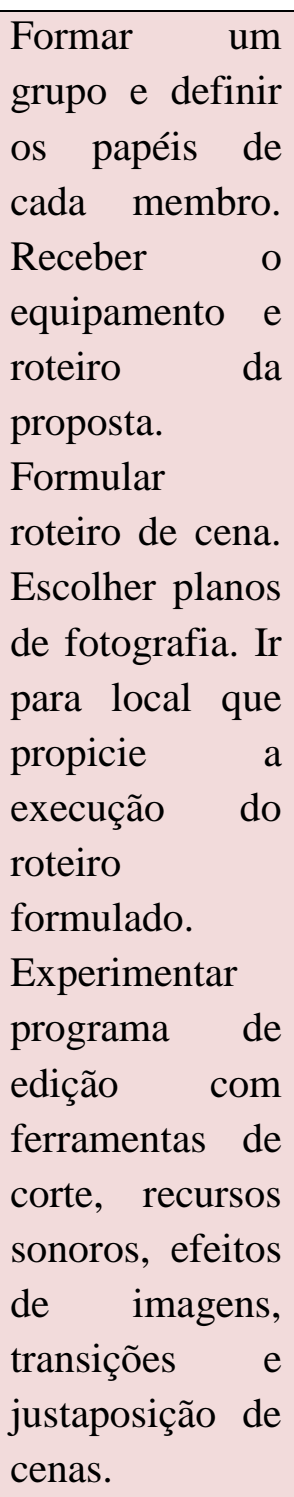 \\
\hline
\end{tabular}




\section{EDUCAÇÃO, ARTES \\ E INCLUSÃO}

VOLUME 11, NÚMERO 1, Ano 2015

ISSN 1984-3178

\begin{tabular}{|c|c|c|c|c|}
\hline & & & processo. & \\
\hline $50 \mathrm{~min}$ & $\begin{array}{lr}\text { Relato } & \text { da } \\
\text { experiência } & \text { de } \\
\text { criação. } & \\
\text { Apresentação } & \text { de } \\
\text { cada } & \text { equipe. } \\
\text { Exibição } & \text { da } \\
\text { produção } & \text { e } \\
\text { discussão. } & \end{array}$ & $\begin{array}{l}\text { Verificar se ouve } \\
\text { troca de saberes } \\
\text { práticos; formação } \\
\text { de } \\
\text { elaboração de cena. } \\
\text { Assistir } \\
\text { resultados } \\
\text { audiovisuais. } \\
\text { Questionar quanto a } \\
\text { possibilidades de } \\
\text { uso da proposta em } \\
\text { sala de aula. }\end{array}$ & 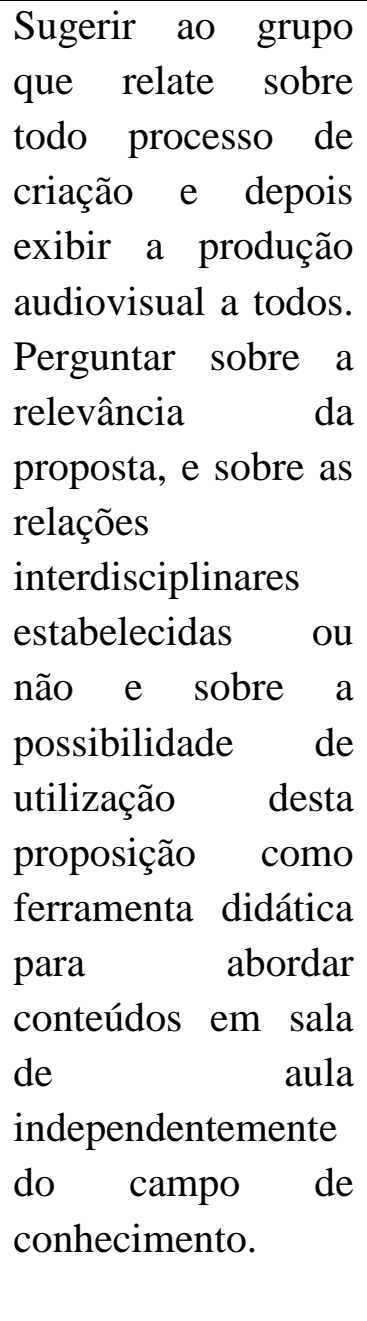 & $\begin{array}{l}\text { Cada grupo é } \\
\text { incitado a } \\
\text { comunicar } \\
\text { oralmente } \\
\text { argumentando e } \\
\text { discutindo } \\
\text { sobre a } \\
\text { formação do } \\
\text { grupo, o roteiro } \\
\text { da cena, as } \\
\text { escolhas } \\
\text { temáticas, o uso } \\
\text { do tablet, as } \\
\text { escolhas dos } \\
\text { planos } \\
\text { fotográficos e } \\
\text { sua realização, } \\
\text { comentar sobre } \\
\text { a forma da } \\
\text { montagem. } \\
\text { Exibir o vídeo } \\
\text { completo. } \\
\text { Sugerir novas } \\
\text { possibilidades. }\end{array}$ \\
\hline $10 \mathrm{~min}$ & $\begin{array}{l}\text { Fechamento } \\
\text { agradecimento }\end{array}$ & $\begin{array}{l}\text { Incentivar o uso de } \\
\text { ferramentas } \\
\text { tecnológicas } \\
\text { dinâmicas } \\
\text { pedagógicas que } \\
\text { envolvam diversos } \\
\text { campos de saberes. } \\
\text { Agradecer pela troca } \\
\text { de experiência. }\end{array}$ & $\begin{array}{l}\text { Comunicação oral } \\
\text { dos realizadores da } \\
\text { oficina. Avisar } \\
\text { sobre o envio da } \\
\text { produção e de } \\
\text { materiais } \\
\text { complementares via } \\
\text { lista de e-mail. }\end{array}$ & $\begin{array}{l}\text { Dúvidas, } \\
\text { esclarecimentos } \\
\text { e } \\
\text { agradecimentos } \\
\text {. }\end{array}$ \\
\hline $\begin{array}{l}\text { Pós- } \\
\text { oficina }\end{array}$ & $\begin{array}{l}\text { Material } \\
\text { complementar }\end{array}$ & $\begin{array}{l}\text { Repassar os vídeos a } \\
\text { todos os envolvidos. } \\
\text { Encaminhar material } \\
\text { bibliográfico e }\end{array}$ & $\begin{array}{lr}\text { Enviar email rom } \\
\text { PDF do livro } \\
\text { MODRO,2008, no } \\
\text { link }\end{array}$ & $\begin{array}{lr}\text { Repassar } & \text { o } \\
\text { email } & \\
\text { profissional } & \text { ou } \\
\text { pessoal } & \text { à }\end{array}$ \\
\hline
\end{tabular}




\section{EDUCAÇÃO, ARTES E INCLUSÃO}

VOLUME 11, NÚMERO 1, Ano 2015

\begin{tabular}{|l|l|l|l|}
\hline demais solicitações & $\begin{array}{l}\text { www.modro.com.br } \\
\text { dos alunos. }\end{array}$ & $\begin{array}{l}\text { equipe da } \\
\text { as apresentações } \\
\text { de slides da oficina durante } \\
\text { e os vídeos } \\
\text { produzidos pelos } \\
\text { grupos. Enviar } \\
\text { outros materiais e e } \\
\text { referências } \\
\text { levantadas durante a } \\
\text { oficina. }\end{array}$ & \\
\hline
\end{tabular}

Fonte: Elaborado pelos autores, 2014.

Esta tabela assume caráter proposicional, podendo servir de referência para experiências similares, com devidas adaptações de acordo com demandas locais. Neste relato foram apresentados alguns acontecimentos decorrentes da proposta acima. 